\title{
AS VOZES DE HUME
}

\section{THE VOICES OF HUME}

Bruno Pettersen*

\section{RESUMO}

Há uma unidade exegética na obra de Hume? Há mesmo uma unidade argumentativa em suas principais obras epistemológicas? A partir de um argumento de Robert Fogelin pensaremos a obra de Hume em uma dialética argumentativa: as vozes de Hume.

PALAVRAS CHAVE: Hume, Fogelin, Ceticismo, Naturalismo.

\begin{abstract}
Is there a unity in Hume's works? Are there in fact an argumentative unity in his main epistemological works? From Robert Fogelin's idea, we will think Hume's work in a dialectic manner: the voices of Hume.
\end{abstract}

KEYWORDS: Hume, Fogelin, Skepticism, Naturalism.

\section{Introdução ao tema}

Um dos temas mais longevos e difíceis no debate sobre a filosofia da Hume é o que discute a orientação de sua filosofia: seria ele um cético ou um naturalista? No século XX uma longa lista de grandes intérpretes ${ }^{1}$ de Hume dedicaram seus livros e artigos para defender uma ou outra orientação. Essa disparidade de opiniões decorre de algumas razões:

1. Hume mudou, se não sua posição, pelo menos seu modo de argumentar entre o Tratado da Natureza Humana (THN) e a Investigação acerca do Entendimento

\footnotetext{
* Doutor em Filosofia e Professor da FAJE - Faculdade Jesuíta de Filosofia e Teologia de Belo Horizonte. Email: brunopettersen@gmail.com.

${ }^{1}$ Alguns dos mais influentes são: Kemp-Smith e o seu The Philosophy of David Hume de 1941. Stroud com o seu Hume em 1977. Fogelin e o Hume's Skepticism de 1985. E Garrett com o Cognition and Commitment in Hume's Philosophy de 1997.
} 
Humano (EHU) ${ }^{2}$. Se em alguns trechos do THN tínhamos um Hume claramente cético, na EHU é difícil encontrar um cético como aquele do THN.

2. Mesmo no interior apenas do THN ou da EHU é possível encontrar trechos um Hume que opta por ser ou cético ou naturalista, onde naquele momento ser um implicava em não ser o outro.

O problema é que optar por uma ou outra posição muda todo o cenário interpretativo. Se cético, Hume é menos propositivo, se naturalista, ele é mais. Se cético, Hume dúvida das faculdades de conhecimento, se naturalista, Hume defende as crenças naturais. E assim por diante.

Uma solução que ficou popular nas últimas décadas do século XX foi a de mesclar as duas posições de Hume em torno do conceito de "ceticismo mitigado" 3 ". Essa tentativa foi em busca da não redução do pensamento de Hume a nenhum dos dois aspectos.

Esse panorama das interpretações de Hume vem aqui a se colocar como pano de fundo para uma proposta ousada e devo infelizmente dizer que não desenvolvida, feita por Robert Fogelin no seu mais recente livro sobre Hume, Hume's Skeptical Crisis: A Textual Study, lançado em 2009. Esse é o terceiro livro de Fogelin sobre Hume e se propõe basicamente a seguir a Quarta Parte do Livro I do THN. Este, ao contrário dos outros livros de Fogelin sobre Hume, não se dedica a uma longa e dedicada interpretação de sua filosofia, mas é um livro que vem para ser um "estudo textual", algo como as aulas de um curso universitário, sobre essas difíceis seções de Hume.

É justamente na introdução deste livro que Fogelin mostra um golpe de gênio sobre a interpretação de Hume: ele deixa de falar do par ceticismo/naturalismo e introduz a ideia de "vozes contrastantes" em Hume. Todavia Fogelin não constrói o seu livro ao redor dessa ideia, e mantém ao longo dele o par ceticismo/naturalismo ${ }^{4}$. Nosso trabalho neste artigo é o de comentar essa ideia de Fogelin e tentar expandi-la um pouco mais do que ele fez.

\footnotetext{
${ }^{2}$ Neste texto será usado o modo usual de se citar Hume. O Tratado da Natureza Humana será citado com sua abreviação THN, seguido de três numerais: o primeiro se refere ao livro, o segundo à parte e o terceiro à seção, finalmente é citada a página da edição brasileira. A Investigação acerca do Entendimento será citada também com sua abreviação EHU, seguida da seção e da página na edição brasileira.

${ }^{3}$ Termo usado pelo próprio Hume no EHU, XII.

${ }^{4}$ Isso talvez tenha ocorrido pelo velho hábito de se escrever a introdução ao término do trabalho, onde podemos ver o trabalho como ele é, e não como gostaríamos que ele fosse. Mas não há qualquer explicação efetiva por parte do próprio Fogelin.
} 


\section{$2 \mathrm{O}$ arquipélago Humeano}

Fogelin neste livro tem em mente um problema de difícil solução em Hume: como compreender de modo coerente a Introdução do THN que é claramente positiva e naturalista, com a Parte IV do Livro I que tem um poderoso caráter cético? Mais ainda: como manter tudo isso com a EHU e seu "ceticismo mitigado"? Podemos pensar em quatro opções:

1. A primeira seria dizer que Hume se contradiz e não há como sustentar sua filosofia. Essa não parece ser uma posição boa porque diminui previamente a obra de Hume.

2. A segunda é pensar que apesar de Hume ter mantido essas posições diferentes, há uma única tendência que é dominante.

3. A terceira posição é unir as posições diferentes e oferecer uma filosofia unitária. Uma alternativa seria pensar em um ceticismo mitigado como uma soma especial entre naturalismo e ceticismo.

4. A quarta e última posição é a de Fogelin e consiste em pensar num Hume "plural”. Ao invés de dizer o que Hume é seria mais interessante ver que sua filosofia tende para um lado ou para outro de acordo com a argumentação daquele momento e que não haveria uma tendência única ou dual, mas uma multiplicidade de "vozes" que se fariam presentes de acordo com o momento. Aqui não temos uma posição de conciliação, pois não é o caso de unir ceticismo e naturalismo, mas sim uma posição que reconhece a força em uma argumentação não-linear.

Vejamos o que Fogelin diz:

[...] há quatro Humes contrastantes ou, pelo menos quatro vozes contrastantes de Hume, que habitam seus escritos. A primeira é o Hume confiante, projetista de uma completa ciência da natureza humana. O segundo é o Hume melancólico, encalhado nas dúvidas pirrônicas que ele parece ser incapaz de abalar. Em terceiro lugar, temos o Hume refinado, modesto nas expectativas e razoavelmente satisfeito com sua sorte. Há também uma quarta voz, ou ponto de vista, encontrada nos escritos de Hume, importante, mas facilmente esquecido. Este é o ponto de vista das pessoas comuns envolvidas nos assuntos da vida cotidiana: o ponto de vista do vulgo. Qual representa o ponto de vista do Hume real? Como eu li o texto, todos os quatro pontos de vista são reais operando em um nível particular de reflexão ${ }^{5}$.

\footnotetext{
${ }^{5}$ No original: "As this development unfolds, there are four contrasting Humes, or at least four contrasting voices of Hume, inhabiting Hume's writings. The first is the confident Hume, projector of a complete science of human nature. The second is the melancholy Hume, wracked with Pyhrronian doubts he seems incapable of shaking. Third, we have the chastened Hume, modest in the expectations and reasonably content with his lot. There is also a fourth voice or standpoint found in Hume's writings, important but easily overlooked. This is the standpoint of the ordinary people engaged in the affairs of daily life: the standpoint of the vulgar. Which standpoint represents the real Hume? As I read the text, all four standpoints are real in operating at particular level of reflection." Pág. 6-7.
} 
Fogelin lê Hume com essas quatro vozes contrastantes, a partir da manifestação de cada voz em um trecho diferente. Fogelin acrescenta apenas mais algumas palavras caracterizando cada "voz", mas não elabora seu argumento, o que é realmente uma pena.

A partir de agora tomaremos como a tarefa deste artigo a de oferecer uma caracterização de cada voz e como elas funcionam no contexto da obra de Hume.

A primeira voz é o Hume confiante. Não é difícil para qualquer leitor habituado com os textos de Hume encontrar um autor que é autoconfiante na sua capacidade para resolver problemas. O lugar mais notável é a Introdução do THN onde ele nos diz que quer fundamentar a "ciência da natureza humana" a qual terá o papel de basear todas as outras ciências, as quais dependem dela. Ele diz assim:

Sempre que experimentos dessa espécie forem criteriosamente reunidos e comparados, podemos esperar estabelecer, com base neles, uma ciência, que não será inferior em certeza, e será muito superior em utilidade, a qualquer outra que esteja ao alcance da compreensão humana. (THN, Introdução, Pág. 24)

Aqui é importante não confundir a confiança com a juventude no THN. Apesar de a EHU ser um pouco menos arrogante do que o THN, Hume ainda acredita na força da sua descrição da natureza humana.

Essa voz confiante pode ser identificada com a interpretação "naturalista" em Hume. Tal interpretação entende Hume como um pesquisador que deseja conhecer a natureza humana a partir do exame "experimental", como ele mesmo atesta no subtítulo do THN. Tal tendência "naturalista" aproxima Hume de autores contemporâneos como Quine.

A segunda voz é a voz melancólica, ou como preferimos "destrutivo-melancólica". Fogelin se refere a uma voz "melancólica" que além do elemento de desalento, também carrega em si a força destrutiva que a melancolia tem. Essa voz é a descrição do poder destrutivo que em Hume podemos ver em todas as suas dúvidas. Assim, dizer voz "melancólica" não retrata tão bem a energia dessa voz e por isso preferimos adaptar o nome dessa voz para "destrutiva-melancólica”, que é menos poética, mas mais direta.

É curioso que logo depois de Fogelin mencionar a voz confiante, ele traz à tona o Hume destrutivo-melancólico. Essa última é uma voz muito especial, encontrada com suas cores mais fortes no final do $\mathrm{THN}^{6}$ e que Hume quis que fosse a conclusão daquele primeiro

\footnotetext{
${ }^{6}$ Ver THN, I, IV, VII.
} 
livro. Fogelin identifica essa voz com o que Hume chama de "cético" nossos termos a ideia do cético radical, hiperbólico. Antes de continuarmos a falar dessa voz cabe aqui uma observação sobre o que significa ser "cético" naquele período do século XVIII.

A caracterização do ceticismo em Hume é profundamente complexa. É certo que o ambiente da modernidade ${ }^{8}$ estava permeado de formas diversas de ceticismo. De um lado temos o ceticismo de Descartes nas Meditações. Por outro lado temos o ceticismo radical de Pierre Bayle. Não podemos nos esquecer do ceticismo de Montaigne que apresenta uma leitura pirrônica. No entanto é difícil dizer o que é a qual das formas de ceticismo Hume se filia. Provavelmente sua ideia sobre o que o ceticismo é não seja o mesmo que pensamos na atual exegese do ceticismo.

O ceticismo parece ser em Hume uma maneira de levantar dúvidas sobre as "operações do entendimento", indicando a debilidade de todo o conhecimento, especialmente da razão. Mas a extensão deste ceticismo é um assunto longo demais para nossa exposição aqui.

A voz "destrutiva-melancólica" é muito mais ampla do que reduzir a fala em um Hume cético. Um Hume "destrutivo-melancólico" é um autor que duvida da possibilidade de conhecer, algumas vezes com mais força e em outros momentos essa melancolia é substituída por uma leve tristeza pelo fato de não ser possível fazer tudo o que ele pretendia.

No THN Hume diz assim:

Essa súbita visão do perigo a que estou exposto me enche de melancolia; e como costumamos a ceder a esta paixão mais que a todas as outras, não posso me impedir de alimentar meu desespero com todas essas reflexões desalentadoras, que o presente tema [ceticismo] me proporciona em tamanha abundância. (THN, I, IV, VII, Pág. 296)

E na Investigação Hume diz assim:

Nenhuma conclusão pode estar mais em conformidade com o ceticismo do que as que trazem revelações relativas à fraqueza e estreita limitação da razão e capacidades humanas. (EHU, VII, Pág. 114)

Veja como ano EHU Hume fala de "fraqueza" do entendimento humano, mas isso não traz necessariamente a tristeza, mas apenas uma constatação da destruição argumentativa que

\footnotetext{
${ }^{7}$ Ver especialmente o EHU, XII.

${ }^{8}$ Popkin, 2003.
} 
ele operou. De todo modo é curioso como a melancolia parece ter diminuído entre as obras de Hume.

A terceira voz é o Hume "modesto". Esta faceta de Hume é aquela que percebe que não é possível a tudo derivar e fundamentar e então escolhe verificar o que é realmente possível de ser realizar. Aqui "modesto" não significa menor, ou com pretensões pequenas, mas significa uma atitude de pesquisa que evita o ceticismo ao apelar para aquilo que é possível conhecer. Essa é outra representação da tendência "naturalista" de Hume.

O Hume modesto é próximo da atitude do cientista que oferece respostas a problemas, mas não espera que possa responder a tudo. Ele diz assim:

\begin{abstract}
Mas, se tais raciocinadores dogmáticos pudessem tornar-se conscientes das estranhas fraquezas do entendimento humano, mesmo em sua mais perfeita condição e ao deliberar da forma mais exata e cuidadosa, essa reflexão naturalmente irá inspirar-lhes mais modéstia e reserva, diminuir a elevada opinião que têm de si mesmos e seu preconceito contra os antagonistas. (...) Há, em geral, um grau de dúvida, cautela e modéstia que, em todos os tipos de exame e decisão, deve sempre acompanhar o verdadeiro raciocinador. (EHU, XII, pgs.217-8)
\end{abstract}

A virtude da modéstia deve sempre acompanhar qualquer pesquisador, especialmente o filósofo que sempre tem diante de si teses que se pretendem universais e metafísicas. É exatamente a tal constatação que a voz modesta de Hume pretende investir.

A quarta voz é a voz do vulgo ${ }^{9}$ que é a representação da visão comum do mundo. Desde o início é importante dizer que, ao contrário do que muitos filósofos insistem, a visão comum é bastante importante na medida em que é ela que afirma algumas trivialidades como o fato de "devemos nos alimentar". Mas, ao mesmo tempo, sabemos que as visões mantidas pelo senso comum são problemáticas. Como é possível articular essa visão do vulgo com o rigor da filosofia? Vejamos como isto se dá a partir de três eixos.

(a) Hume diz que o senso comum é um bom modo de mitigar o ceticismo excessivo. Em termos humeanos, uma dúvida excessiva, por mais persuasiva que pareça é rapidamente eliminada se nos voltarmos às práticas da vida comum. Isso não quer dizer que o ceticismo é respondido pelo senso comum, mas sim que nossas crenças e práticas comuns têm uma força que ultrapassa qualquer argumento racional. Hume afirma tal ideia em uma das passagens mais belas de sua obra:

\footnotetext{
${ }^{9}$ A expressão "opinião do vulgo" é comum na obra de Hume e descreve o que chamaríamos hoje de "senso comum".
} 
Felizmente ocorre que, sendo a razão incapaz de dissipar essas nuvens, a própria natureza o faz, e me cura dessa melancolia e delírio filosóficos, tornando mais branda essa inclinação da mente, ou então fornecendo-me alguma distração e alguma impressão sensível mais vivida, que apagam todas essas quimeras. Janto, jogo uma partida de gamão, converso e me alegro com meus amigos; após três ou quatro horas de diversão, quando quero retornar essas especulações, elas me parecem tão frias, forçadas e ridículas, que não me sinto mais disposto a levá-las adiante. Encontro-me aqui, portanto, absoluta e necessariamente determinado a viver, a falar e agir como as outras pessoas, nos assuntos da vida corrente. (THN, I, IV, VII, Pág. 301)

(b) Um segundo ponto é a própria caracterização que Hume faz da filosofia. Ele diz em certo momento que "as decisões filosóficas nada mais são do que reflexões da vida ordinária, sistematizas e corrigidas" (EHU, XII, Pág. 219). Nesse sentido Hume estabelece que o ponto de partida para o conhecimento é o senso comum, mas esse por si só não traz conhecimento, para que isso seja possível é necessário que a reflexão possa metodizar o que pensamos comumente.

(c) Mas para confirmar que Hume não é completamente um filósofo do senso comum podemos ver em muitos lugares, como em suas reflexões no EHU sobre o caso dos milagres, que a opinião do vulgo é facilmente manipulada, especialmente neste caso, pelos relatos extraordinários e maravilhosos. Hume diz assim:

[...] mas que tudo procede da propensão usual da humanidade para o fantástico, e que, embora essa inclinação possa ocasionalmente ser freada pelo bom senso e instrução, nunca se poderá extirpá-la completamente da natureza humana. (EHU, X, Pág. 166)

Com isso Hume compreende que o senso comum é profundamente marcado por erros e manipulações, o que evidentemente não o torna inválido, apenas problemático.

Com estes três pontos configuramos a posição de Hume em relação ao vulgo. Mas o que é mais interessante é que essa sua posição é perfeitamente condizente com interpretações naturalistas e céticas, ou seja, com as vozes precedentes.

Se pensarmos em um cético clássico como Sexto Empírico, veremos que ele diz que o cético deve viver, dentre outras regras, com a determinação dos sentidos e de acordo com as leis e "práticas comuns"10. Isso não quer dizer que os céticos assumem que as percepções são verdadeiras, mas apenas que elas são fortes o suficiente para nos guiar na vida comum.

\footnotetext{
${ }^{10}$ Ver Sexto Empírico, Outlines of Pyhrronism I, 23-24. Neste trecho Sexto indica que o cético se guia a partir das aparências com os seguintes critérios: São quatro os critérios, a saber: (1) a orientação da natureza, (2) a necessidade das sensações, (3) a aceitação das leis e costumes e (4) o ensinamento e condução das atividades técnicas.
} 
Ao mesmo tempo, naturalistas como Quine concordam de modo integral com Hume, onde o primeiro diz no seu famoso artigo "Os dois dogmas do empirismo" que: "A ciência é uma continuação do senso comum, e ela continua a utilizar o recurso do senso comum de expandir a ontologia para simplificar a teoria ${ }^{11}$."

A voz do vulgo é a aquela que acomoda algumas das tendências de Hume e permite articular tanto o ceticismo quanto o naturalismo, sem que qualquer uma destas teses seja sobrevalorizada em relação à outra.

\section{O coro de Hume}

Imaginamos que a vantagem de falar em quatro vozes em Hume e ao mesmo passo abandonar a necessidade de estabelecer o embate entre naturalismo e ceticismo é que no caso das vozes não há preferência para qualquer lado. Todas as vozes são acomodadas como partes diferentes do discurso de Hume. Este é um tipo de argumentação não linear que não pretende erguer um argumento único ao final, mas sim construir experiências filosóficas em cada passo do argumento de uma obra.

No entanto, ao falar de vozes estamos retornado à um problema semelhante que havia no par naturalismo e ceticismo: aparentemente as quatro vozes são contraditórias entre si. Como exemplo, podemos pensar que a fala da voz "confiante" parecer ser contraditória à fala da voz "modesta". Parece que voltamos ao problema que dá origem a esta nova intepretação de Fogelin.

Para que o problema seja solucionado devemos perceber que a introdução das vozes como ferramenta exegética não quer eliminar a dificuldade, mas sim encontrar um modo de fazer as várias tendências serem compreendidas como parte de uma obra. Mas como exatamente deveríamos resolver esta equação?

Nossa hipótese é que as quatro vozes funcionam com um coro, onde cada um canta uma parte que sozinha não faz sentido. Sozinha uma voz representa apenas uma parte da música. O problema passa a ser quando tentamos isolar uma parcela do pensamento de Hume e tentamos nomeá-la. Isso certamente conflitará com outras parcelas de seu texto. O ideal é pensar essas vozes como sempre presentes em todos os momentos do texto de Hume, contudo

\footnotetext{
${ }^{11}$ Quine, 1975, Pág. 253.
} 
dependendo do trecho essa voz diminui ou silencia para dar lugar a uma mais alta, para então ali nos contar parte da história que é precisa.

Um lugar interessante para pensarmos essa ideia é o livro de Hume Diálogos sobre a religião natural ${ }^{12}$. Muitas vezes os intérpretes se perguntam qual das vozes ali é a posição de Hume. Certamente a posição que nos lembra mais frequentemente a posição de Hume é a de Philo, mas os Diálogos só funcionam do modo que Hume provavelmente queria quando pensamos no conflito e na interação das posições, e não quando tentamos localizar uma só posição. Muitas vezes na ânsia de colocar etiquetas nas teses os intérpretes esquecem o quão brilhante era o texto de Hume e que essa beleza vem da mistura não linear destas orientações filosóficas.

As vozes de Hume funcionam como os personagens dos Diálogos. Das quatro vozes, a voz "destrutiva-melancólica" e a "confiante" são as mais flutuantes e em muitos lugares chegam a se silenciar. Isso porque elas são muito fortes e querem ressaltar temas que funcionam apenas naquele momento. Mas as vozes "modesta" e a do "vulgo" são as mais constantes, elas refletem o tom mais sóbrio e reflexivo que a obra de Hume tem, mas mesmo elas são reduzidas. Mas é um erro pensá-las em isolado. Podemos falar que uma das vozes impera mais aqui ou ali, mas para entendermos realmente o que Hume quer dizer é importante reuni-las.

Duas teses devem ser colocadas sobre essa hipótese das vozes: em primeiro lugar ela não é uma alegoria para outra teoria, falar em vozes é querer dizer que o texto de Hume não funciona como uma única tendência e que vez ou outra ele se move em direção de uma maior ou menor radicalidade de seu argumento; e segundo essas vozes não devem ser vistas como características de Hume, elas são uma ferramenta exegética para a compreensão do porquê Hume tem diferentes estilos em seu texto.

Antes de passar para o próximo ponto uma advertência deve ser feita: essa não é uma explicação exaustiva da posição de Hume. Com a hipótese das vozes não queremos dizer tudo o que Hume escreveu pode ser lido somente de acordo com essa hipótese. Antes o que nos levou a ver que essa hipótese é interessante é somente o fato de que ela oferece um meio eficiente de explicar as questões exegéticas que existem na argumentação de Hume, sem reduzi-lo a nenhum termo.

${ }^{12}$ Hume, David. Diálogos sobre a religião natural, 1992. 


\section{Uma implicação}

Se essa hipótese exegética oferecida por Fogelin realmente for possível, que implicações ela teria para a análise da obra de Hume? Mais do que isso, como a hipótese das "vozes" pode ajudar-nos a entender melhor as teses de Hume? Para responder a estas questões precisaríamos de muito mais espaço do que temos aqui, dessa maneira, esboçaremos nesta seção um projeto de análise da obra de Hume a partir dessa hipótese. Para isso ofereceremos uma pergunta e sugeriremos uma estratégia de resposta a partir da hipótese das vozes. A pergunta é a seguinte: Como pensar a epistemologia de Hume a partir do balanço das vozes?

Podemos dividir a epistemologia de Hume a partir das quatro vozes:

A primeira é representada pela voz "confiante" com a sua teoria da mente/ideais. Essa teoria é sempre apresentada por Hume com grande força e como fundamento da sua ciência da natureza humana, sendo que no THN Hume é ainda mais confiante do que na EHU. Contudo se bem observarmos estes dois livros, apesar de poderem ser percebidas diferenças entre eles, no caso da teoria das ideias, Hume a apresenta sempre como a mesma energia. $\mathrm{O}$ Hume confiante está sempre no início de ambas as obras.

A segunda é representada pelas "dúvidas céticas" de Hume sobre o fundamento racional das inferências acerca das questões de fato. Essa é a voz "destrutiva-melancólica". Contudo, dependendo do livro, as dúvidas quanto a nossa capacidade de conhecimento receberam uma intensidade diversa. O THN tem essa voz mais forte do que a EHU, principalmente o fator "melancólico".

Tanto no THN quanto na EHU Hume é bastante incisivo para demonstrar o fato de que nossas crenças não podem ser baseadas na razão. Na EHU essa argumentação é conduzida naturalmente para a próxima voz, a modesta. No THN a voz modesta só aparece após a voz melancólica dominar o texto. A melancolia que é quase ausente na EHU, sendo a contrário poderosíssima no THN. De todo o modo, essa voz não é exclusiva do THN sendo ela a responsável pelo aparecimento da próxima voz.

A terceira é a voz "modesta", onde depois de ter constatado a debilidade de nosso conhecimento, Hume passa a descrever o conhecimento de outra maneira. O termo "modesto" passa a ser pensado como uma limitação das faculdades racionais somado à uma aposta nos mecanismos naturais de funcionamento da mente. Neste ponto não há muita diferença entre o tom do THN e da EHU, exceto que talvez no THN Hume tenda a exagerar mais na voz destrutiva-melancólica. 
A última parte é a voz do "vulgo". Depois de descrever o mecanismo do conhecimento, resta a Hume mostrar que precisamos no fiar nas crenças comuns, mas metodizadas pela razão. Nesse caso, como comentamos ao falar dessa voz, não se trata de obedecer simplesmente a voz do vulgo. Hume desenvolverá toda uma teoria da probabilidade para explicar como podemos aceitar uma crença em bases mais seguras e refletidas do que o vulgo faz constantemente.

De toda maneira, Hume sabe bem algo que todo o filósofo deveria saber: por mais incríveis que sejam as teorias filosóficas que ditam com nossas crenças, no final do dia agimos como qualquer pessoa, de acordo com a vida comum. Este ponto é o que reúne o THN e a EHU. Nos dois livros Hume acredita que o único modo real de se livrar das garras do ceticismo excessivo é através de seguir a vida de acordo com regras comuns. Essa voz é a única que pode realmente dar o tom final dos textos de Hume, muito embora para existir ela dependa das outras.

Nesta rápida proposta de análise interpretativa separamos por cada parte do argumento o lugar das vozes. Mas isso não quer dizer de forma alguma que as vozes são localizadas. É preciso trabalhar em conjunção sem que haja sobreposição de uma sobre a outra.

\section{Conclusão}

Devemos terminar esse texto com uma voz modesta. Fogelin disse muito pouco sobre sua hipótese que neste texto tentamos desdobrar. Para nós, Fogelin foi brilhante para colocar a questão, mas sem exatamente explicar sua intuição. Imagino que se perguntássemos para um grupo de estudiosos de Hume se o escocês tem essas vozes em seu pensamento, acredito que a enorme maioria dos pesquisadores diria que sim, mas se perguntássemos se Hume é cético ou naturalista, certamente teríamos uma grande disputa. É ai que reside a força da hipótese de Fogelin, uma hipótese que concilia as interpretações de Hume ao não reduzi-lo a nenhuma delas.

\section{Referências}

FOGELIN, Robert J. Hume's skeptical crisis: a textual study. Oxford; New York: Oxford University Press, 2009.

FOGELIN, Robert J. Hume's Skepticism in the 'Treatise of Human Nature'. London and Boston, MA: Routledge \& Kegan Paul. 1985. 
GARRETT, Don. Cognition and Commitment in Hume's Philosophy. New York: Oxford University Press, 1997.

KEMP-SMITH, Norman. The Philosophy of David Hume: A Critical Study of its Origins and Central Doctrines. Londres: Macmillan, 1941.

HUME, David. An enquiry concerning human understanding: a critical edition. Oxford Clarendon Press; New York Oxford University Press 2006.

HUME, David. Diálogos sobre a religião natural. São Paulo: Martins Fontes, 1992.

HUME, David. Investigações sobre o entendimento humano e sobre os princípios da moral. São Paulo: Ed. Unesp, 2004.

HUME, David. Tratado da natureza humana: uma tentativa de introduzir o método experimental de raciocínio nos assuntos morais. 2. ed. rev. e ampl. São Paulo: Editora UNESP, 2009.

HUME, David. A treatise of human nature: a critical edition. Oxford: Clarendon Press; New York: Oxford University Press, 2007.

POPKIN, Richard Henry. The history of scepticism: from Savonarola to Bayle. Rev. and expanded ed. Oxford; New York: Oxford University Press, 2003.

QUINE, W.V.O. “Dois Dogmas do Empirismo”. Tradução de LIMA, Marcelo. São Paulo: Abril Cultural, 1975. São Paulo: Abril Cultural, 1975. (Coleção os Pensadores).

SEXTUS, Empiricus. Outlines of scepticism. Trad: J. Annas e J. Barnes. Cambridge [England]; New York: Cambridge University Press, 2000.

STROUD, B. Hume. London: Routledge e Kegan Paul. 1977. 